\title{
Role of antiviral therapy in reducing recurrence and improving survival in hepatitis B virus-associated hepatocellular carcinoma following curative resection (Review)
}

\author{
CHAOHUI ZUO ${ }^{1,2^{*}}$, MAN XIA ${ }^{2,3}$, QUNFENG WU ${ }^{2}$, HAIZHEN ZHU ${ }^{1}$, JINGSHI LIU ${ }^{1}$ and CHEN LIU ${ }^{2 *}$ \\ ${ }^{1}$ Department of Gastroduodenal and Pancreatic Surgery, Translation Medicine Research Center of Liver Cancer, \\ Hunan Province Tumor Hospital and Affiliated Tumor Hospital of Xiangya Medical School, \\ Central South University, Changsha, Hunan 410013, P.R. China; ${ }^{2}$ Department of Pathology, Immunology and \\ Laboratory Medicine and Shands Cancer Center, University of Florida, Gainesville, FL 32610-0275, USA; \\ ${ }^{3}$ Department of Gynaecological Oncology, Hunan Province Tumor Hospital and Affiliated Tumor Hospital of \\ Xiangya Medical School, Central South University, Changsha, Hunan 410013, P.R. China
}

Received June 17, 2014; Accepted November 7, 2014

DOI: $10.3892 / \mathrm{ol} .2014 .2727$

\begin{abstract}
Hepatocellular carcinoma (HCC) is one of the major causes of cancer-related mortality worldwide, with the majority of cases associated with persistent hepatitis $\mathrm{B}$ virus (HBV) or hepatitis $\mathrm{C}$ virus infection. In particular, chronic HBV infection is a predominant risk factor for the development of HCC in Asian and African populations. Hepatic resection, liver transplantion and radiofrequency ablation are increasingly used for the curative treatment of HCC, however, the survival rate of HCC patients who have undergone curative resection remains unsatisfactory due to the high recurrence rate. $\mathrm{HCC}$ is a complex disease that is typically resistant to the most commonly used types of chemotherapy and radiotherapy; therefore, the development of novel treatment strategies is required to improve the survival rate of this disease. A high viral load of HBV DNA is the most important correctable risk factor for HCC recurrence, for example nucleos(t)ide analogs improve the outcome following curative resection of HBV-associated $\mathrm{HCC}$, and interferon- $\alpha$ exhibits antitumor activity against various types of cancer via direct inhibitory effects on tumor cells, anti-angiogenesis, enhanced
\end{abstract}

Correspondence to: Professor Chaohui Zuo, Department of Gastroduodenal and Pancreatic Surgery, Translation Medicine Research Center of Liver Cancer, Hunan Province Tumor Hospital and Affiliated Tumor Hospital of Xiangya Medical School, Central South University, 383 Tongzipo Road, Changsha, Hunan 410013, P.R. China

E-mail: zuochaohui@vip.sina.com

${ }^{*}$ Contributed equally

Key words: hepatocellular carcinoma, hepatitis B virus, recurrence, interferon- $\alpha$, survival rates, curative resection, sorafenib, transatheter arterial chemoembolization immunogenicity of tumors, immunomodulatory effects and liver dysfunction. In the present review, antiviral treatment for $\mathrm{HBV}$-associated $\mathrm{HCC}$ is described as a strategy to reduce recurrence and improve survival.

\section{Contents}

1. Introduction

2. HBV and the risk of $\mathrm{HCC}$ recurrence

3. Mechanism of IFN- $\alpha$ in HBV-associated HCC

4. Role of IFN- $\alpha$ on HBV-associated HCC recurrence following surgery

5. Synergistic effects of IFN- $\alpha$ and other agents on $\mathrm{HBV}$-associated HCC recurrence following surgery

6. Conclusion

\section{Introduction}

In males, liver cancer is the fifth most frequently diagnosed type of cancer and the second most common cause of cancer-related mortality, worldwide. However, in females, liver cancer is the seventh most frequently diagnosed type of cancer and the sixth most common cause of cancer-related mortality worldwide. . An estimated 748,300 new cases of liver cancer and 695,900 cancer-related mortalities occurred worldwide in 2008 (1), half of which were estimated to have occurred in China $(2,3)$. The highest liver cancer rates occur in East and Southeast Asia, and in Central and Western Africa, whereas the lowest rates occur in South-Central and Western Asia, as well as in Northern and Eastern Europe. Globally, rates are more than twice as high in males as in females. Among the various types of primary liver cancer, hepatocellular carcinoma (HCC) is the predominant histological subtype, with chronic hepatitis $\mathrm{B}$ virus $(\mathrm{HBV})$ and hepatitis $\mathrm{C}$ virus $(\mathrm{HCV})$ infection attributable to $\sim 75-80 \%$ of HCC cases worldwide $(4,5)$. In particular, chronic $\mathrm{HBV}$ infection is a predominant risk factor for $\mathrm{HCC}$ 
development in Asian and African populations (6,7). HCC is a rare type of cancer in terms of its continued increase in incidence over a number of years $(8,9)$. Additionally, HCC is the most relevant example of virus and inflammation-associated cancer; $\mathrm{HBV}$ and $\mathrm{HCV}$ are etiological factors for HCC, with persistent active hepatitis and hepatic fibrosis important in the development of HCC. The prognosis of HCC associated with hepatitis virus infection remains poor due to the high rate of HCC recurrence following surgery $(10,11)$ and progressive liver dysfunction that results in hepatic failure. Hepatic resection, liver transplantation and radiofrequency ablation (RFA) are increasingly used for the curative treatment of HCC, and are able to achieve good local control of the disease (12). Liver transplantation is the most radical treatment for HCC, as well as for underlying liver diseases, such as chronic HBV or HCV infection $(13,14)$; however, a shortage of donors hinders the efficacy of liver transplantation (15). In patients with small HCC, percutaneous RFA demonstrated similar local control and long-term survival rates to hepatectomy and, notably, percutaneous RFA is associated with a lower complication rate and shorter hospital stay (16). Although percutaneous RFA may provide small HCC patients with therapeutic effects similar to those of hepatic resection, it is more likely to result in the incomplete treatment of small HCCs located at specific sites in the liver; therefore, an open surgical approach to hepatic resection may be a preferable treatment strategy (17). Furthermore, RFA appears to be a reasonable strategy for the treatment of very small HCCs $(<2 \mathrm{~cm})$ with no technical contraindications, in which complete necrosis is likely to occur. In larger nodules ( $>2 \mathrm{~cm}$ and particularly $>3 \mathrm{~cm}$ ) and/or in tumor locations in which RFA is not expected to be effective or safe, surgical resection is preferred (18).

Surgery remains the most effective HCC treatment strategy with curative potential; liver resection is the gold standard for patients with resectable HCC that develops in otherwise healthy patients $(19,20)$ and offers an acceptable outcome for carefully selected HCC patients $(21,22)$. Refinements of surgical techniques and staging systems have resulted in five-year survival rates of $\sim 50-70 \%$ following surgical resection $(23,24)$. The application of advanced surgical techniques and instrumentation decreases blood loss, increases positive outcomes, such as survival and quality of life, and decreases the requirement for the Pringle maneuver compared with portal triad clamping (25-28). Although liver resection appears to be the most effective strategy for the treatment of HCC, patients who undergo curative resection often exhibit a high rate of relapse $(29,30)$ and only $\sim 10-20 \%$ of patients with HCC are currently eligible for surgical intervention. Considering its apparent superiority to liver transplantation and local ablative therapy, surgical resection is likely to remain the primary approach for patients who present with very early- and early-stage HCC. Furthermore, the risk factors of tumor size, tumor nodules, vascular invasion, chronic viral infection, liver function and portal pressure have been identified as prognostic predictors of recurrence following liver resection (31-33). HCC development is a multistep process that typically occurs over a number of years; numerous mutations accumulate in the cellular DNA, resulting in malignant transformation, growth and metastatic behavior of the cell. Recently, it has become apparent that the tumor microenvironment, as well as the tumor cell itself, are key in the development of the tumor. For example, in the liver cancer microenvironment, a direct association appears to exist between the role of inflammation and the development of cirrhosis (34-36). Multicentric recurrence of HCC is closely associated with persistent active hepatitis and hepatic fibrosis, and costimulation affects intrahepatic immune responses, appearing to be important in immune tolerance, immune injury and immune abnormalities in patients exhibiting chronic HBV infection (37-39). Thus, the present review highlights the mechanism of $\mathrm{HBV}$ induction of HCC and discusses the current trends in antiviral therapy following curative resection of HCC.

\section{HBV and the risk of $\mathrm{HCC}$ recurrence}

HCC will almost invariably occur in a histologically abnormal liver, with the existence of chronic liver disease representing a potential risk for the development of this type of tumor. In addition to the specific viral mechanisms that may be directly carcinogenic to the liver, chronic necroinflammation and the accumulation of reactive oxygen species contribute to carcinogenesis via chromosomal injury (40). Cirrhosis, the end-stage consequence of hepatic inflammation that results in nodular transformation of the liver, is considered to be a premalignant condition, independent of its etiology.

Numerous studies have attempted to summarize the pathogenesis of HBV-associated carcinogenesis, as well as the viral and host factors that may increase the risk of developing HCC. HBV is the predominant cause of chronic hepatitis, cirrhosis and HCC (41-43); a high viral load of HBV is crucial for the development of chronic liver disease and a previous study using long term tracking of HBV viral load determined the association between HBV viral load and the risk of developing HCC (44). Furthermore, epidemiological studies have examined differences in HCC carcinogenesis due to HBV DNA load (45), however, the mechanisms by which HBV DNA load causes differences in malignant transformation remains unclear. It has recently been demonstrated that high HBV load is associated with an increased risk of developing HCC in patients with chronic HBV (46), and HBV DNA load has recently been found to be associated with $\mathrm{HCC}$ recurrence following curative treatment (47).

Sohn et al (48) investigated the predictive role of HBV DNA and HBV surface antigen (HBsAg) levels in the early and late recurrence of $\mathrm{HCC}$ following curative resection in patients with $\mathrm{HBV}$-associated HCC. A total of 248 patients underwent curative resection for $\mathrm{HBV}$-associated early-stage HCC (group one, solitary tumor; group two, $<5$-cm diameter or multinodular tumor; group three, $\leq 3$ tumors and $<3-\mathrm{cm}$ diameter). Multivariate analysis identified risk factors for early recurrence, including the presence of microvascular invasion [hazard ratio $(\mathrm{HR}), 3.86 ; \mathrm{P}<0.001$ ], preoperative HBV DNA levels of $\geq 20,000 \mathrm{IU} / \mathrm{ml}(\mathrm{HR}, 2.77 ; \mathrm{P}<0.001)$ and des- $\gamma$-carboxy prothrombin levels of $\geq 40 \mathrm{mAU} / \mathrm{ml}(\mathrm{HR}, 1.76 ; \mathrm{P}=0.045)$. HBV DNA levels were associated with early recurrence, whereas HBsAg levels were associated with late recurrence following curative resection for $\mathrm{HBV}$-associated HCC. Additionally, $\mathrm{Xia}$ et al (49) reported that high serum hyaluronic acid levels and high HBV viral load were the principle prognostic factors associated with local recurrence following complete 
radiofrequency ablation for $\mathrm{HBV}$-associated small $\mathrm{HCC}$. As HBV DNA load changes with the administration of antiviral agents, patients with a high viral load at the time of HCC treatment who receive antiviral agents subsequently demonstrated differences in HBV DNA load compared with those who did not receive antiviral agent therapy. An et al (50) examined 188 patients with $\mathrm{HBV}$-associated HCC who underwent curative resection and performed multivariate analysis to identify the following independent predictors of $\mathrm{HCC}$ recurrence in all participants: A tumor size of $>5 \mathrm{~cm}$, Child-Pugh class B, vascular invasion and $>10^{4}$ copies/ml HBV DNA at resection. This high HBV replication state was the chief predictor of a poor outcome following resection of $\mathrm{HBV}$-associated HCC. By contrast, multivariate analysis revealed that a sustained suppression of $<10^{4}$ copies/ml HBV DNA was the sole factor that resulted in low HCC recurrence and an extended survival period, acting as a strong protective factor for long-term recurrence-free and overall survival . During HBV-induced HCC initiation, chronic inflammation typically facilitates the evolution of HBV mutants which promote HCC development. Therefore, the development of efficient preventative and therapeutic strategies against HCC in HBV-infected patients may rely on investigations into the effects of inflammation on HBV-induced HCC initiation and progression (51-54).

\section{Mechanism of IFN- $\alpha$ in HBV-associated HCC}

Interferon- $\alpha$ (IFN- $\alpha$ ) belongs to the type I IFN family of cytokines, which were originally identified and isolated for their antiviral properties (55-57). Subsequent studies revealed that IFN- $\alpha$ exhibits antitumor activity against various types of cancer by directly inhibiting tumor cells; this includes preventing angiogenesis, enhancing the immunogenicity of tumors and performing immunomodulatory effects on tumor cells $(58,59)$. Chronic HBV infection has been treated with IFN- $\alpha$ for $>20$ years and IFN- $\alpha$ was one of the first agents approved by the Food and Drug Administration (FDA) for this purpose (60). IFN- $\alpha$ induces the expression of various antiviral host proteins, such as protein kinase $\mathrm{R}$ and myeloid differentiation primary response protein 88 . To exert its antitumor activity, IFN- $\alpha$ may accelerate tumor necrosis factor-induced tumor cell apoptosis by upregulating Fas gene expression (61); however, opposing studies have demonstrated that pretreatment with IFN- $\alpha$ inhibits tumor necrosis factor-related apoptosis-inducing ligand (TRAIL)-mediated nuclear factor- $\kappa \mathrm{B}(\mathrm{NF}-\kappa \mathrm{B})$ activation, thereby increasing the response of hepatoma cells to the TRAIL-induced apoptosis signal (62). Thus, for patients with $\mathrm{HBeAg}$-positive chronic $\mathrm{HBV}$, percutaneous endoscopic gastrostomy (PEG) combined with IFN- $\alpha$ offers superior efficacy on the basis of $\mathrm{HBeAg}$ and HBsAg seroconversion, as well as HBV DNA suppression. As a result of these features, novel therapeutic regimens based on combinations of PEG IFN- $\alpha$ with third-generation nucleos(t)ide analogs (NUCs), such as entecavir and tenofovir, are being developed to increase the rate of HBsAg seroclearance, which remains the ideal endpoint for all $\mathrm{HBe} A g$-negative chronic HBV patients.

Liu et al (63) determined that IFN- $\alpha$ may improve chemosensitivity in tumor cells by inhibiting HBV $\mathrm{X}$ protein $(\mathrm{HBx})$-induced activation of the $\mathrm{NF}-\kappa \mathrm{B}$ signaling pathway.
Additionally, it was proposed that IFN- $\alpha$ may aid in reverting previously acquired chemoresistance. Consistent with the findings that IFN- $\alpha$ inhibits $\mathrm{HBx}-$ mediated activation of $\mathrm{NF}-\kappa \mathrm{B}$, Liu et al concluded that $\mathrm{HBx}$-induced resistance to therapeutic agents was associated with the activation of the $N F-\kappa B$ signaling pathway. These results indicate that IFN- $\alpha$ may be a useful adjuvant treatment to chemotherapy for enhancing the response of $\mathrm{HBV}$-associated $\mathrm{HCC}$ via $\mathrm{HBx}$-triggered $\mathrm{NF}-\kappa \mathrm{B}$ activation. The mechanisms involved in the process whereby HCC establishes an immunologically tolerant tumor environment remain poorly characterized. Cabrera et al (64) showed that HCC patients have blunted T cell immunity that is partly associated with elevated levels of soluble interleukin-2 receptor $\alpha$ chains, supporting a novel immuno-inhibitory role for this soluble receptor. In HepG2 and HepG2.2.15 cells, Hou et al (65) revealed a novel role of IFN- $\alpha$ and microRNA (miR) 146a in HBV immunopathogenesis, and provided a potential target for the therapeutic recovery of anti-HBV effects.

Conclusive studies in relevant experimental systems have yet to be conducted to determine the molecular mechanisms by which IFN- $\alpha$ suppresses HBV replication, however, it is known that the HBV genome contains an IFN-stimulated response element (IRSE) (66). Belloni et al (67) identified that IFN- $\alpha$ decreases the transcription rate of pregenomic (pgRNA) and subgenomic RNA in the covalently closed circular DNA (cccDNA) minichromosome of HBV, inhibiting HBV replication. However, this experiment was only conducted in cultured cells in which HBV was undergoing replication, and in mice whose livers had been repopulated with human hepatocytes and infected with HBV. The administration of IFN- $\alpha$ in these two systems resulted in transcriptional inhibition by multiple mechanisms: cccDNA-bound histones were hypoacetylated, transcriptional corepressors were actively recruited to the cccDNA, and binding of signal transducer and activator of transcription 1 (STAT1) and STAT2 to active cccDNA was reduced. IRSE-mutant HBV exhibited a reduction in pgRNA transcription and was resistant to IFN- $\alpha$-induced repression; therefore, the abovementioned inhibitory effects of IFN- $\alpha$ were associated with IRSE via epigenetically-mediated HBV cccDNA transcriptional repression. Additional understanding of this molecular mechanism may assist in the development of effective novel therapeutic strategies.

In order to conduct more relevant experiments regarding the association between IFN- $\alpha$ and hepatitis infection, Yang et al (68) established a hepatoma cell line; cells were isolated from the liver tumor tissue of a male patient with chronic HCV infection (Hunan Provincial Tumor Hospital, Changsha, China) to create the HLCZ01 cell lines, which was the first cell line to support the entire life cycle of HBV and HCV. The ability of IFN- $\alpha$ to inhibit HBV replication in HBV-infected HLCZ01 cells was examined and it was identified that IFN- $\alpha$ inhibits HBV replication in the culture system by decreasing the transcription of viral pregenomic RNA. In a systematic review of 11 studies of the effect of IFN- $\alpha$ and NUC therapy on the outcome of HBV infection over the previous 10 years, Sung et al (69) determined that IFN- $\alpha$ or NUC treatment significantly reduced the risk of developing HCC. Although IFN- $\alpha$ therapy benefited patients with cirrhosis, NUCs benefited those with non-cirrhosis and HBeAg-positive 
infections. Considering the abovementioned studies, sustained HBV suppression induced by IFN- $\alpha$ and NUC therapy may be necessary to reduce the development of HCC in HBV-infected patients.

Thus, the following mechanisms contribute to the antitumor effect of IFN: First, IFN may cause the induction of pro-apoptotic genes; second, IFN may directly effect malignant cells; third, IFN may inhibit angiogenesis; and last, it may augment antitumor immune responses and improve liver function.

\section{Role of IFN- $\alpha$ on HBV-associated HCC recurrence fol- lowing surgery}

Although curative resection represents the preferred method for extending the survival of HCC patients, the survival rate remains poor due to the high rate of HCC recurrence (70-72). A systematic review of thirteen randomized control trials indicated that the beneficial effects of adjuvant IFN- $\alpha$ therapy reduced the rate of recurrence and IFN- $\alpha$ did not appear to improve the survival of $\mathrm{HCV}$-associated $\mathrm{HCC}$ patients following curative therapy (73). However, in a retrospective cohort study conducted by Qu et al (74), $568 \mathrm{HBV}$-associated HCC patients who underwent curative resection were investigated; Postoperative IFN- $\alpha$ therapy $\left(5 \times 10^{6} \mathrm{U}\right.$ IFN- $\alpha$; 3 doses/week) was received by 101 patients for 18 months and clinicopathological factors were compared between patients who did or did not receive postoperative IFN- $\alpha$ therapy. Patients who received postoperative IFN- $\alpha$ therapy exhibited higher overall survival rates [HR, 0.612; 95\% confidence interval (CI), 0.422-0.889; $\mathrm{P}=0.010)$, however, no significant difference was identified in the disease-free survival rates between the two groups (HR, 0.786; 95\% CI, 0.597-1.035; $\mathrm{P}=0.086$ ). Additionally, multivariate analysis revealed that postoperative IFN- $\alpha$ therapy was an independent factor for significant reductions in overall survival rates (HR, 0.611; 95\% CI, 0.421-0.887; $\mathrm{P}=0.010$ ) and early recurrence rates (HR, 0.562; 95\% CI, 0.375-0.840; $\mathrm{P}=0.005$ ). This previous study demonstrated that IFN- $\alpha$ therapy for patients exhibiting HBV-associated HCC following curative resection prevents early recurrence rates and improves overall survival. In addition, a different retrospective study identified that patients with a persistent level of $\geq 4 \log _{10}$ copies/ml HBV DNA upon resection and follow-up demonstrated the highest risk of recurrence (HR, 4.129; $\mathrm{P}<0.001$ ); and $\geq 4 \log _{10}$ copies $/ \mathrm{ml}$ HBV DNA upon resection was the most significant risk factor for HCC recurrence. Furthermore, the risk of recurrence was significantly reduced in patients who underwent postoperative IFN- $\alpha$ treatment following resection (75). In a randomized clinical trial $(\mathrm{n}=235)$, Sun et al $(76)$ compared treatment ( 3 doses/week of $5 \times 10^{6} \mathrm{U}$ IFN- $\alpha$ intramuscularly for 18 months) and control groups following resection. Statistical analysis was based on the method of intent-to-treat and determined that IFN- $\alpha$ treatment improved the overall survival of patients with $\mathrm{HBV}$-associated $\mathrm{HCC}$ following curative resection, possibly by postponing recurrence. Additionally, in 27 randomized controlled trials predominantly conducted in Asian populations, comparing adjuvant with no adjuvant therapy, Wang et al (77) reported that adjuvant chemotherapy, internal radiation and heparanase inhibitor PI-88 therapy failed to improve recurrence-free survival or overall survival rates, however, adjuvant IFN- $\alpha$ therapy did improve recurrence-free and overall survival rates. Furthermore, the combination of systemic and transhepatic arterial chemotherapy was not recommended for HCC following potentially curative treatment, therefore, postoperative IFN- $\alpha$ therapy may be beneficial for HBV-associated HCC patients $(78,79)$.

The benefits of adjuvant IFN- $\alpha$ therapy for patients who have undergone resectable HCC are controversial. In a total of 268 Tawainese patients, a recent phase III randomized study of IFN- $\alpha 2 b$ therapy following curative resection for HBV-and $\mathrm{HCV}$-associated $\mathrm{HCC}$ demonstrated no preventative effect on HBV or HCV recurrence (80). Therefore, the role of IFN- $\alpha$ in improving survival may be associated with different patients responses (81). miRNAs can be used as biomarkers for diverse types of malignancies. Notably, miRNAs can be utilized to investigate various cancer phenotypes, used as therapeutic agent targets or used as the therapeutic agent itself (82-84). IFN- $\alpha$ may prolong the survival period in specific patients, however, the response is often unsatisfactory as the identification of suitable patients who are likely to benefit from this therapy is difficult. Therefore, the development of molecular tools for the classification of patients with respect to their response to IFN- $\alpha$ therapy is required. In 214 patients from two independent, prospective, randomized, controlled trials of adjuvant IFN therapy, Ji et al (85) employed quantitative reverse transcriptase-polymerase chain reaction to determine miRNA expression levels and assess their association with survival rates and response to IFN- $\alpha$ therapy. This analysis identified that the expression patterns of miRNAs in liver tissue differ between male and female HCC patients, and that the miRNA-26 expression status of such patients is associated with survival and response to IFN- $\alpha$ adjuvant therapy. Furthermore, Ji et al (86) developed a miR26-diagnostic test, which may assist in the selection of candidate HCC patients who exhibit a favorable overall survival response to adjuvant IFN- $\alpha$ treatment. Such a test may prevent unnecessary IFN- $\alpha$ treatment for individuals who do not exhibit improved survival, thereby providing them with an opportunity to undergo alternative treatment modalities. Hou et al (87) identified that the expression of IFN-stimulated retinoic acid inducible gene-I (RIG-I) was significantly downregulated in human HCC tissues. Additionally, a lower RIG-I expression level was associated with a shorter survival period and a poorer response to IFN- $\alpha$ therapy, indicating that RIG-I is a useful prognostic factor and IFN- $\alpha$ response predictor for HCC patients. RIG-I appears to enhance the IFN- $\alpha$ response by amplifying the activation of the STAT1 transcription factor, which in turn amplifies IFN- $\alpha$ effector signaling. Furthermore, this previous study identified that RIG-I deficiency promotes the initiation of HCC development and determined that hepatic RIG-I expression levels are lower in male compared with female individuals. Thus, the RIG-I gene may act as a tumor suppressor in HCC and contribute to HCC gender disparity. Similarly to the miR26-diagnostic test, the implementation of a RIG-I test may prevent unnecessary IFN- $\alpha$ treatment for individuals who do not exhibit improved survival from this type of therapy, thereby, providing them with an opportunity to undergo alternative treatment modalities. 


\section{Synergistic effects of IFN- $\alpha$ and other agents on HBV-as- sociated HCC recurrence following surgery}

Transcatheter arterial chemoembolization (TACE) is a therapeutic treatment for HCC patients, which particularly implements its therapeutic effect in patients exhibiting moderate-to-advanced grade, inoperable HCC (88-90). However, the benefits of adjuvant TACE for patients with resectable HCC are controversial, for example, a number of clinical trials have identified no evidence supporting the benefits of adjuvant TACE for non-high-risk patients $(91,92)$. Furthermore, Breunig et al (93) determined that the administration of adjuvant TACE produced a significant survival benefit in patients with risk factors of recurrence. For patients with large HCC tumors with multiple intrahepatic metastases, debulking surgery followed by IFN- $\alpha$ and 5 -FU combination therapy offers the possibility of long-term survival; however, optimal debulking is essential for prolonged survival during subsequent treatment (94), for example, postoperative adjuvant TACE is typically administered to HCC patients at a high risk of recurrence $(95,96)$. In 27 patients with large HCC tumors and multiple intrahepatic metastases, Tanaka et al (97) performed IFN- $\alpha$ and TACE combination therapy following maximal liver tumor resection, and identified that this treatment strategy offered the possibility of long-term survival despite the late stage of the disease. In a preliminary report of 33 patients, Kumamoto et al (98) proposed that combination of subcutaneous IFN- $\alpha$ and intra-arterial 5-FU infusion therapy may delay the development of recurrence and reduce the number of recurrent nodules in the remnant liver following curative resection. As a result, combination therapy may improve the prognosis of advanced HCC patients with portal vein invasion or intrahepatic metastasis. The prognosis of $\mathrm{HBV}$-associated HCC is principally influenced by the risk of recurrence following curative resection, thus, the prevention and treatment of recurrent tumors may be required to improve the long-term survival rates of HCC patients. In a retrospective study ( $\mathrm{n}=120)$, Yan et al (99) reported that postoperative administration of TACE prevents early HCC recurrence and the administration of antiviral therapy prevents the late recurrence of HCC. Therefore, antiviral and TACE combination therapy is proposed for the treatment of HCC patients with a high risk of recurrence following liver resection.

Sorafenib (BAY 43-9006; Nexavar; Bayer Pharmaceuticals Corp., West Haven, CT, USA) is a multikinase inhibitor, which can be orally administered. Sorafenib inhibits tumor cell proliferation by targeting the Raf/mitogen-activated protein kinase/extracellular signal-regulated kinase (Raf/MEK/ERK) signaling pathway and exerts an antiangiogenic effect by targeting a number of tyrosine kinases: Vascular endothelial growth factor-2 (VEGFR-2), VEGFR-3 and platelet-derived growth factor receptor- $\beta(100,101)$. In preclinical models, sorafenib demonstrated dose-dependent activity against a wide range of tumor types, including HCC (102); it inhibited cell growth, induced apoptosis and downregulated the anti-apoptotic protein Mcl-1 via a Raf/MEK/ERK-independent mechanism. Sorafenib is approved by the US FDA for the treatment of HCC, based on phase two and three clinical trial data from patients with advanced metastatic HCC; the sorafenib treatment group demonstrated close to a three-month survival advantage over the untreated group $(103,104)$. Furthermore, liver-directed therapy exhibited a response rate of $>70 \%$, and sorafenib has previously produced reasonable toxicity profiles and a slight improvement in therapeutic efficacy when administered in combination with liver-directed therapies (105); therefore, sorafenib must be considered as a viable treatment strategy for HCC patients, within the context of all currently available treatment options In a pilot study of 31 patients, Wang et al (106) performed a Cox regression analysis and identified that the administration of sorafenib was the only prognostic variable associated with HCC recurrence (HR, 0.24; 95\% CI, 0.08-0.75; $\mathrm{P}=0.014)$. This previous study indicated that sorafenib may be an adjuvant therapy for HCC to prevent early recurrence following hepatic resection. Furthermore, the cumulative recurrence-free survival rate demonstrated the preventive effectiveness of sorafenib; sorafenib provides a significant survival benefit for prevention in HCC patients with a high risk of recurrence $(107,108)$.

Kusano et al (109) demonstrated a synergistic antiproliferative effect of combination therapy on HAK-1B cells in vitro. Additionally, a significant reduction in tumor volume and weight was observed in vivo HAK-1B and KIM1 tumor cells administered with combination therapy, although synergistic effects were not obvious. The density of cluster of differentiation 34-positive microvessels was significantly lower and cleaved caspase-3-positive apoptotic cell numbers were higher in the sorafenib group and the combination group compared with the control or PEG-IFN- $\alpha 2 b$ groups in HAK-1B and KIM-1 tumors. Furthermore, the Ki67 labeling index was significantly lower in the combination group compared with the control group in KIM-1 tumors. Thus, the results of the study conducted by Kusano et al (109) indicate that combination therapy may be a more effective strategy for the treatment of HCC cases with variable sensitivity to the antitumor effects of singular sorafenib or PEG-IFN- $\alpha 2 b$ therapy. Additionally, xenograft experiments conducted by Wang et al (110) identified that IFN- $\alpha$ and sorafenib combination therapy on exhibited an enhanced effect on tumor growth inhibition and apoptosis induction in vivo, providing rationale for the clinical application of IFN- $\alpha$ and sorafenib combination therapy in HCC treatment, which may be use in clinical practice in the near future.

\section{Conclusion}

Currently, patients exhibiting high HBV DNA levels at HCC onset demonstrate significantly higher HCC recurrence rates compared with patients exhibiting low HBV DNA levels $(111,112)$. The efficacy of tertiary prevention of HCC with any agent, including chemotherapy, HBV therapy or IFN, has yet to be determined, and safe and effective chemotherapy for HCC-recurrence has yet to be established, however, tumor prevention appears to be most effective in patients with chronic HBV infection (113). Treatment with PEG-IFN may be suboptimal as it results in significant adverse effects and NUCs may induce resistance. It is important to achieve HBsAg loss and anti-HBsAg conversion in therapy, as these outcomes produce the most favorable outcome (114).

In conclusion, the effects of antiviral therapy on reducing recurrence and improving survival in HBV-associated HCC 
following curative resection were reviewed in the present study. IFN- $\alpha$ may increase survival in patients administered with IFN- $\alpha$ therapy by preventing HCC recurrence following liver resection. Notably, the present review determined that HBV replication should also be monitored, as sustained HBV activation or relapse is significantly associated with HCC development and recurrence. Individualized antiviral therapy is important by measuring miRNAs to prevent unnecessary IFN- $\alpha$ treatment for those individuals who do not experience improved survival. RIG-I expression is a useful prognostic marker and IFN- $\alpha$-response predictor for HCC patients. The combination of IFN- $\alpha$ and TACE is only proposed for prevention in HCC patients with high risk of recurrence. Furthermore, sorafenib is a newly introduced therapeutic agent, which offers improved prevention for HCC patients with high risk of recurrence. Future studies should focus on the synergistic role IFN- $\alpha$ and sorafenib in the management of chronic HBV-associated $\mathrm{HCC}$ following curative resection, and $\mathrm{HBsAg}$ loss and anti-HBV conversion, the development of safe and affordable agents, as well as management strategies to improve sustained or maintained HBV suppression, should be the future aims for the management of chronic HBV-associated HCC.

\section{Acknowledgements}

The present study was supported by a grant from the Changsha City Third Science and Techology Project of China (grant no. K1403380-31) awarded to Professor Chaohui Zho.

\section{References}

1. Jemal A, Bray F, Center MM, Ferlay J, Ward E and Forman D: Global cancer statistitics. CA Cancer J Clin 61: 69-90, 2011.

2. Ding J and Wang H: Multiple interactive factors in hepatocarcinogenesis. Cancer Lett 346: 17-23, 2014.

3. Ferlay J, Shin HR, Bray F, Forman D, Mathers C and Parkin DM: Estimates of worldwide burden of cancer in 2008: GLOBOCAN 2008. Int J Cancer 127: 2893-2917, 2010.

4. Miamen AG, Dong $\mathrm{H}$ and Roberts LR: Immunotherapeutic approches to hepatocellular carcinoma treatment. Liver Cancer 1: 226-237, 2012.

5. Yuen MF, Hou JL and Chutaputti A; Asia Pacific Working Party on Prevention of Hepatocellular Carcinoma: Hepatocellular carcinoma in the Asia pacific region. J Gastroenterol Hepatol 24: 346-53, 2009.

6. Trepo C: A brief history of hepatitis milestones. Liver Int 34 (Suppl 1): 29-37, 2014.

7. Ishikawa T: Anti-viral therapy to reduce recurrence and improve survival in hepatitis B virus-related hepatocellular carcinoma. World J Gastroenterol 19: 8861-8866, 2013.

8. Malek NP, Schmidt S, Huber P, Manns MP and Greten TF: The diagnosis and treatment of hepatocellular carcinoma. Dtsch Arztebi Int 111: 101-106, 2014.

9. Lopez LJ and Marrero JA: Hepatocellular carcinoma. Curr Opin Gastroenterol 20: 248-253, 2004.

10. Shen Y, Lin ZZ, Hsu CH, Hsu C, Hsu C, Shao YY and Cheng AL: Clinical trials in hepatocellular carcinoma: an update. Liver Cance 2: 345-364, 2013.

11. Sasaki K, Matsuda M, Ohkura Y, Kawamura Y, Inoue M, Hashimoto M, Ikeda K, Kumada H and Watanabe G: In hepatocellular carcinomas, any proportion of poorly differentiated components is associated with poor prognosis after hepatectomy. World J Surg 38: 1147-1153, 2014.

12. Lin S, Hoffmann K and Schemmer P: Treatment of hepatocellular carcinoma: a systematic review. Liver Cancer 1: 144-158, 2012.

13. Singal AK, Guturu P, Hmoud B, Kuo YF, Salameh H and Wiesner RH: Evolving frequency and outcomes of liver transplantation based on etiology of liver disease. Transplanation 95 755-760, 2013.
14. Jiang L, Yan L, Wen T, et al: Hepatitis B prophylaxis using lamivudine and individualized low-dose hepatitis B immunoglobulin in living donor liver transplantation. Transplant Proc 45: 2326-2330, 2013.

15. Vitale A, Volk M and Cillo U: Transplant benefit for patients with hepatocellular carcinoma. World J Gastroenterol 19: 9183-9188, 2013.

16. Fang Y, Chen W, Liang X, Li D, Lou H, Chen R, Wang K and Pan H: Comparison of long-term effectiveness and complications of radiofrequency ablation with hepatectomy for small hepatocellular carcinoma. J Gastroenterol Hepatol 29: 193-200, 2014.

17. Wang Y, Luo Q, Li Y, Deng S, Wei S and Li X: Radiofrequency ablation versus hepatic resection for small hepatocellular carcinomas: a meta-analysis of randomized and nonrandomized controlled trials. PloS One 9: e84484, 2014.

18. Cucchetti A, Piscaqlia F, Cescon M, Ercolani G and Pinna AD: Systematic review of surgical resection vs radiofrequency ablation for hepatocellular carcinoma. World J Gastroenterol 19: 4106-4188, 2013.

19. Yang T, Zhang J, Lu JH, Yang LQ, Yang GS, Wu MC and Yu WF: A new staging system for resectable hepatocellular carcinoma: comparison with six existing staging systems in a large Chinese cohort. J Cancer Res Clin Oncol 137: 739-750, 2011.

20. Maluccio M and Covey A: Recent progress in understanding, diagnosing, and treating hepatocellular carcinoma. CA Cancer J Clin 62: 394-399, 2012.

21. DuBray BJ Jr, Chapman WC and Anderson CD: Hepatocellular carcinoma: a review of the surgical approaches to management. Mo Med 108: 195-198, 2011.

22. Salhab M and Canelo R: An overview of evidence-based management of hepatocellular carcinoma: a meta-analysis. J Cancer Res Ther 7: 463-475, 2011.

23. Young AL, Adair R, Prasad KR, Toogood GJ and Lodge JP: Hepatocellular carcinoma within a noncirrhotic, nonfibrotic, seronegative liver: surgical approaches and outcomes. J Am Coll Surg 214: 174-183, 2012.

24. Gluer AM, Cocco N, Laurence JM, Johnston ES, Hollands MJ, Pleass HC, Richardson AJ and Lam VW: Systematic review of actual 10-year survival following resection for hepatocellular carcinoma. HPB (Oxford) 14: 285-290, 2012.

25. Rahbari NN, Wente MN, Schemmer P, Diener MK, Hoffmann K, Motschall E, Schmidt J, Weitz J and Büchler MW: Systematic review and meta-analysis of the effect of portal triad clamping on outcome after hepatic resection. Br J Surg 95: 424-432, 2008.

26. Liao X, Chen L, Fu W and Zhou J: Heparin-binding epidermal growth factor-like grow th factor protects rat intestine after portal triad clamping. Growth Factors 31: 74-80, 2013.

27. Wang PF, Li CH, Chen YW, Zhang AQ, Cai SW and Dong JH: Preserving hepatic artery flow during portal triad blood inflow occlusion improves remnant liver regeneration in rats after partial hepatectomy. J Surg Res 181: 329-336, 2013.

28. Rammohan A, Sathyanesan J, Ramaswami S, Lakshmanan A, Senthil-Kumar P, Srinivasan UP, Ramasamy R and Ravichandran P: Embolization of liver tumors: Past, present and future. World J Radiol 4: 405-412, 2012.

29. Choi JY: Treatment algorithm for intermediate and advanced stage hepatocellular carcinoma: Korea. Oncology 81 (Suppl 1): 141-147, 2011.

30. Fan ST, Mau Lo C, Poon RT, et al: Continuous improvement of survival outcomes of resection of hepatocellular carcinoma: a 20-year experience. Ann Surg 253: 745-758, 2011.

31. Xi T, Lai EC, Min AR, Shi LH, Wu D, Xue F, Wang K, Yan Z, Xia Y, Shen F, et al: Adjuvant transatheter arterial chemoembolization after curative resection of hepatocellular carcinoma: a non-randomized comparative study. Hepatogastroenterology 59: 1198-1203, 2012.

32. Shirable K, Wakiyama S, Gion T, Motomura K, Koyanagi T, Sakamoto $\mathrm{S}$ and Nagaie T: Clinicopathological risk factors linked to recurrence pattern after curative hepatic resection for hepatocellular carcinoma - results of 152 resected cases. Hepatogastroenterology 54: 2084-2087, 2007.

33. Ho CM, Wu CY, Lee PH, Lai HS, Ho MC, Wu YM and Hu RH: Analysis of the risk factors of untransplantable recurrence after primary curative resection for patients with hepatocellular carcinoma. Ann Surg Oncol 20: 2526-2533, 2013.

34. Severi T, van Malenstein H, Verslype C and van Pelt JF: Tumor initiation and progression in hepatocellular carcinoma: risk factors, classification, and therapeutic targets. Acta Pharmacol Sin 31: 1409-1420, 2010.

35. Wang $\mathrm{H}$ and Chen L: Tumor microenvironment and hepatocellular carcinoma metastasis. J Gastroenterol Hepatol 28 (Suppl 1):43-48, 2013. 
36. Xu J, Xu HY, Zhang Q, Song F, Jiang JL, Yang XM, Mi L, Wen N, Tian R, Wang L, et al: HAb18G/CD147 functions in invasion and metastasis of hepatocellular carcinoma. Mol Cancer Res 5: 605-614, 2007.

37. Zhong B, Huang MP, Yin GQ and Gao X: Effects of costimulation on intrahepatic immunopathogenesis in patients with chronic HBV infection. Inflamm Res 63: 217-229, 2014.

38. Wong GL, Chan HL, Tse YK, Lo AO and Wong VW: On-treatment alpha-fetoprotein is a specific tumor marker for hepatocellular carcinoma in patients with chronic hepatitis B receiving entecavir. Hepatology 59: 986-995, 2014.

39. Abu-Amara M and Feld JJ: Does antiviral therapy for chronic hepatitis B reduce the risk of hepatocellular carcinoma? Semin Liver Dis 33: 157-166, 2013.

40. Brechot C, Kremsdorf D, Soussan P, Pineau P, Dejean A, Paterlini-BrechotP and Tiollais P: Hepatitis B virus (HBV)-related hepatocellular carcinoma (HCC): molecular mechanisms and novel paradigms. Pathol Biol (Paris) 58: 278-287, 2010.

41. Kew MC: Hepatocellular carcinoma in African blacks: Recent progress in etiology and pathogenesis. World J Hepatol 2: 65-73, 2010.

42. Chen L, Zhang Q, Chang W, Du Y, Zhang H and Cao G: Viral and host inflammation-related factors that can predict the prognosis of hepatocellular carcinoma. Eur J Cancer 48: 1977-1987, 2012.

43. Chan HL and Sung JJ: Hepatocellular carcinoma and hepatitis B virus. Semin Liver Dis 26: 153-161, 2006.

44. Wu CF, Yu MW, Lin CL, Liu CJ, Shih WL, Tsai KS and Chen CJ: Long-term tracking of hepatitis B viral load and the relationship with risk for hepatocellular carcinoma in men. Carcinogenesis 29: 106-112, 2008.

45. Sun Y, Chen TY, Lu PX, Wang JB, Wu Y, Zhang QN, Qian GS and Tu H: Relationship between serum hepatitis B virus DNA load and hepatocellular carcinoma in Qidong, China: a cohort follow-up study of 14 years. Zhonghua Yi Xue Za Zhi 92: 1874-1877, 2012 (In Chinese).

46. Pan W, Cheng G, Xing H, Shi J, Lu C, Wei J, Li L, Zhou C, Yuan Q, Zhou L and Yang M: Leukocyte telomere lengthrelated rs621559 and rs398652 genetic variants influence risk of HBV-related hepatocellular carcinoma. PLoS One 9: e110863, 2014.

47. Ke Y, Wang L, Li LQ and Zhong JH: Nucleos(t)ide analogues to treat hepatitis B virus-related hepatocellular carcinoma after radical resection. World J Hepatol 6: 653-659, 2014.

48. Sohn W, Paik YH, Kim JM, Kwon CH, Joh JW, Gwak GY, Choi MG, Lee JH, Koh KC, Paik SW and Yoo BC: HBV DNA and HBsAg levels as risk predictors of early and late recurrence after curative resection of HBV-related hepatocellular carcinoma Ann Surg Oncol 21: 2429-2435, 2014.

49. Xia F, Lai EC, Lau WY, Ma K, Li X, Bie P and Qian C: High serum hyaluronic acid and HBV viral load are main prognostic factors of local recurrence after complete radiofrequency ablation of hepatitis B-related small hepatocellular carcinoma. Ann Surg Oncol 19: 1284-1291, 2012

50. An HJ, Jang JW, Bae SH, Choi JY, Cho SH, Yoon SK, Han JY, Lee KH, Kim DG and Jung ES: Sustained low hepatitis B viral load predicts good outcome after curative resection in patients with hepatocellular carcinoma. J Gastroenterol Hepatol 25: 1876-1882, 2010

51. Deng Y, Du Y, Zhang Q, Han X and Cao G: Human cytidine deaminases facilitate hepatitis B virus evolution and link inflammation and hepatocellular carcinoma. Cancer Lett 343: 161-171, 2014.

52. McMahon BJ: Chronic hepatitis B virus infection. Med Clin North Am 98: 39-54, 2014

53. Su CH, Lin Y and Cai L: Genetic factors, viral infection, other factors and liver cancer: an update on current progress. Asian Pac J Cancer Prev 14: 4953-4960, 2013.

54. Shi L, Feng Y, Lin H, Ma R and Cai X: Role of estrogen in hepatocellular carcinoma: is inflammation the key? J Transl Med 12: 93, 2014.

55. Höner $\mathrm{Zu}$, Siederdissen $\mathrm{C}$ and Cornberg M: The role of HBsAg levels in the current management of chronic HBV infection. Ann Gastroenterol 27: 105-112, 2014.

56. Khaliq S, Latief $\mathrm{N}$ and Jahan S: Role of different regions of the hepatitis $\mathrm{C}$ virus genome in the therapeutic response to interferon-based treatment. Arch Virol 159: 1-15, 2014.

57. Qashqari H, Al-Mars A, Chaudhary A, Abuzenadah A, Damanhouri G, Alqahtani M, Mahmoud M, El Sayed Zaki M, Fatima K and Qadr I: Understanding the molecular mechanism(s) of hepatitis $\mathrm{C}$ virus $(\mathrm{HCV})$ induced interferon resistance. Infect Genet Evol 19: 113-119, 2013.
58. Herzer K, Hofmann TG, Teufel A, Schimaski CC, Moehler M, Kanzler S, Schulze-Bergkamen H and Galle PR: IFN- $\alpha$-induced apoptosis in hepatocellular carcinoma involves promyelocytic leukemia protein and TRAIL independently of p53. Cancer Res 69: 855-862, 2009.

59. Lamm D, Brausi M, O'Donnell MA and Witjes A: Interferon alfa in the treatment paradigm for non-muscle-invasive bladder cancer. Urol Oncol 32: 35.e21-35.e30, 2014

60. Yang YF, Zhao W, Zhong YD, Yang YJ, Shen L, Zhang N and Huang P: Comparison of the efficacy of thymosin alpha-1 and interferon alpha in the treatment of chronic hepatitis B: a meta-analysis. Antiviral Res 77: 136-141, 2008

61. Schweizer M, Mätzener P, Pfaffen G, Stalder H and Peterhans E: 'Self' and 'nonself' manipulation of interferon defense during persistent infection: bovine viral diarrhea virus resists alpha/beta interferon without blocking antiviral activity against unrelated viruses replicating in its host cells. J Virol 80: 6926-6935, 2006.

62. Wilden H, Schirrmacher V and Fournier P: Important role of interferon regulatory factor (IRF)-3 in the interferon response of mouse macrophages upon infection by Newcastle disease virus. Int J Oncol 39: 493-504, 2011.

63. Liu, Y, Lou G, Wu W, Shi Y, Zheng M and Chen Z: Interferon- $\alpha$ sensitizes HBx-expressing hepatocarcinoma cells to chemotherapeutic drugs through inhibition of $\mathrm{HBx}$-mediated NF- $\mathrm{BB}$ activation. Virol J 10: 168, 2013.

64. Cabrera R, Ararat M, Cao M, Xu Y, Wasserfall C, Atkinson MA, Liu C and Nelson DR: Hepatocellular carcinoma immunopathogenesis: clinical evidence for global $\mathrm{T}$ cell defects and an immunomodulatory role for soluble CD25 (sCD25). Dig Dis Sci 55: 484-495, 2010.

65. Hou ZH, Han QJ, Zhang C, Tian ZG and Zhang J: miR146a impairs the IFN-induced anti-HBV immune response by downregulating STAT1 in hepatocytes. Liver Int 34: 58-68, 2014.

66. Alcantara FF, Tang H and McLachlan A: Functional characterization of the interferon regulatory element in the enhancer 1 region of the hepatitis B virus genome. Nucleic Acids Res 30 2068-2075, 2002.

67. Belloni L, Allweiss L, Guerrieri F, Pediconi N, Volz T, Pollicino T, Petersen J, Raimondo G, Dandri M and Levrero M: IFN- $\alpha$ inhibits HBV transcription and replication in cell culture and in humanized mice by targeting the epigenetic regulation of the nuclear cccDNA minichromosome. J Clin Invest 122 529-537, 2012.

68. Yang D, Zuo C, Wang X, Meng X, Xue B, Liu N, Yu R, Qin Y, Gao Y, Wang Q, et al: Complete replication of hepatitis B virus and hepatitis $\mathrm{C}$ virus in a newly developed hepatoma cell line. Proc Natl Acade Sci USA 111: E1264-E1273, 2014.

69. Sung JJ, Tsoi KK, Wong VW, Li KC and Chan HL: Meta-analysis: Treatment of hepatitis B infection reduces risk of hepatocellular carcinoma. Aliment Pharmacol Ther 28: 1067-1077, 2008.

70. Xiaobin F, Shuguo Z, Jian Z, Yudong Q, Lijian L, Kuansheng M, Xiaowu L, Feng X, Dong Y, Shuguang W, et al: Effect of the pringle maneuver on tumor recurrence of hepatocellular carcinoma after curative resection (EPTRH): a randomized, prospective, controlled multicenter trial. BMC Cancer 12: 340, 2012.

71. Torzilli G, Donadon M and Cimino M: Are tumor exposure and anatomical resection antithetical during surgery for hepatocellular carcinoma? A critical review. Liver Cancer 1: 177-182, 2012.

72. Chen JA, Shi M, Li JQ and Qian CN: Angiogenesis: multiple masks in hepatocellular carcinoma and liver regeneration. Hepatol Int 4: 537-547, 2010.

73. Zhung L, Zeng X, Yang Z and Meng Z: Effect and safety of interferon for hepatocellular carcinoma: a systematic review and meta-analysis. PloS One 8: e61361, 2013.

74. Qu LS, Jin F, Huang XW and Shen XZ: Interferon- $\alpha$ therapy after curative resection prevents early recurrence and improves survival in patients with hepatitic B virus-related hepatocellular carcinoma. J Surg Oncol 102: 796-801, 2010.

75. Qu LS, Jin F, Huang XW and Shen XZ: High hepatitis B viral load predicts recurrence of small hepatocellular carcinoma after curative resection. J Gastrointest Surg 14: 1111-1120, 2010.

76. Sun HC, Tang ZY, Wang L, Qin LX, Ma ZC, Ye QH, Zhang BH, Qian YB, Wu ZQ, Fan J, et al: Postoperative interferon $\alpha$ treatment postponed recurrence and improved overall survival in patients after curative resection of HBV-related hepatocellular carcinoma: a randomized clinical trial. J Cancer Res Clin Oncol 132: 458-465, 2006. 
77. Wang J, He XD, Yao N, Liang WJ and Zhang YC: A meta-analysis of adjuvant therapy after potentially curative treatment for hepatocellular carcinoma. Can J Gastroenterol 27 : 351-363, 2013

78. Tan ZM and Sun BC: Effects of antiviral therapy on preventing liver tumorigenesis and hepatocellular carcinoma recurrence. World J Gastroenterol 19: 8895-8901, 2013.

79. Sun P, Yang X, He RQ, Hu QG, Song ZF, Xiong J and Zheng QC: Antiviral therapy after curative treatment of hepatitis $B / C$ virus-related hepatocellular carcinoma: A systematic review of randomized trials. Hepatol Res 44: 259-269, 2014.

80. Chen LT, Chen MF, Li LA, Lee PH, Jeng LB, Lin DY, Wu CC, Mok KT, Chen CL, Lee WC, et al; Disease Committee of Adjuvant Therapy for Postoperative Hepatocellular Carcinoma, Taiwan Cooperative Oncology Group, National Health Research Institutes, Zhunan, Taiwan: Long-term results of a randomized, observation controlled, phase III trial of adjuvant interferon Alfa-2b in hepatocellular carcinoma after curative resection. Ann Surg 255: 8-17, 2012.

81. Takaoka A, Hayakawa S, Yanai H, Stoiber D, Negishi H, Kikuchi H, Sasaki S, Imaki S, Imai K, Shibue T, et al: Integration of interferon- $\alpha / \beta$ signalling to $\mathrm{p} 53$ responses in tumour suppression and antiviral defence. Nature 424: 516-523, 2003.

82. Slack FJ and Weidhaas JB: MicroRNA in cancer prognosis. N Eng J Med 359: 2720-2722, 2008.

83. Lujambio A and Lowe SW: The microcosmos of cancer. Nature 482: 347-355, 2012.

84. Kong YW, Ferland-McCollough D, Jackson TJ and Bushell M: microRNAs in cancer management. Lancet Oncol 13: e249-e258, 2012.

85. Ji J, Shi J, Budhu A, Yu Z, Forgues M, Roessler S, Ambs S, Chen Y, Meltzer PS, Croce CM, et al: MicroRNA expression, survival, and response to interferon in liver cancer. N Eng J Med 361: 1437-1447, 2009.

86. Ji J, Yu Z, Yu Z, Forgues M, Uenishi T, Kubo S, Wakasa K, Zhou J, Fan J, Tang ZY, et al: Development of a miR-26 companion diagnostic test for adjuvant interferon-alpha therapy in hepatocellular carcinoma. Int J Biol Sci 9: 303-312, 2013.

87. Hou J, Zhou Y, Zheng Y, Fan J, Zhou W, Ng IO, Sun H, Qin L, Qiu S, Lee JM, et al: Hepatic RIG-I predicts survival and interferon- $\alpha$ therapeutic response in hepatocellular carcinoma. Cancer Cell 25: 49-63, 2014.

88. Zhao Y, Cai G, Zhou L, Liu L, Qi X, Bai M, Li Y, Fan D and Han G: Transarterial chemoembolization in hepatocellular carcinoma with vascular invasion or extrahepatic metastasis: A systematic review. Asia Pac J Clin 9: 357-364, 2013.

89. Lencioni R: Chemoembolization for hepatocellular carcinoma. Semin Oncol 39: 503-509, 2012.

90. Chen S, Chen J, Xi W, Xu W and Yin G: Clinical therapeutic effect and biological monitoring of p53 gene in advanced hepatocellular carcinoma. Am J Clin Oncol 37: 24-29, 2014.

91. Zhong JH and Li LQ: Postoperative adjuvant transarterial chemoembolization for participants with hepatocellular carcinoma: A meta-analysis. Hepatol Res 40: 943-953, 2010.

92. Matsuda M, Omata F, Fuwa S, Saida Y, Suzuki S, Uemura M, Ishii N, Iizuka Y, Fukuda K and Fujita Y: Prognosis of patients with hepatocellular carcinoma treated solely with transcatheter arterial chemoembolization: risk factors for one-year recurrence and two-year mortality (preliminary data). Intern Med 52: $847-853,2013$

93. Breunig IM, Shaya FT, Hanna N, Seal B, Chirikov VV and Daniel Mullins C: Transarterial chemoembolization treatment: association between multiple treatments, cumulative expenditures, and survival. Value Health 16: 760-768, 2013.

94. Nagano H, Sakon M, Eguchi H, Kondo M, Yamamoto T, Ota H, Nakamura M, Wada H, Damdinsuren B, Marubashi S, et al: Hepatic resection followed by IFN- $\alpha$ and 5-FU for advanced hepatocellular carcinoma with tumor thrombus in the major portal branch. Hepatogastroenterology 54: 172-179, 2007.

95. Choi JW, Park JY, Ahn SH, Yoon KT, Ko HK, Lee do Y, Lee JT, Kim KS, Choi JS, Han KH, et al: Efficacy and safety of transarterial chemoembolization in recurrent hepatocellular carcinoma after curative surgical resection. Am J Surg Oncol 32: 564-569, 2009.

96. LiKW,Li X, Wen TFand Lu WS: The effect of postoperative TACE on prognosis of HCC: an update. Hepatogastroenterology 60 248-251, 2013.
97. Tanaka K, Yabushita Y, Nakagawa K, Kumamoto T, Matsuo K, Taguri $\mathrm{M}$ and Endo I: Debulking surgery followed by intraarterial 5-fluorouracil chemotherapy plus subcutaneous interferon alfa for massive hepatocellular carcinoma with multiple intrahepatic metastases: a pilot study. Eur J Surg Oncol 39: 1364-1370, 2013.

98. Kumamoto T, Tanaka K, Matsuo K, Takeda K, Nojiri K, Mori K, Taniguchi K, Matsuyama R, Ueda M, Akiyama H, et al: Adjuvant hepatic arterial infusion chemotherapy with 5-Fluorouracil and interferon after curative resection of hepatocellular carcinoma: a preliminary report. Anticancer Res 33: 5585-5590, 2013

99. Yan Q, Ni J, Zhang GL, Yao X, Yuan WB, Zhou L and Zheng SS: Efficacy of postoperative antiviral combined transcatheter arterial chemoembolization therapy in prevention of hepatitis B-related hepatocellular carcinoma recurrence. Chin Med J (Engl) 126: 855-859, 2013.

100. Xie B, Wang DH and Spechcer SJ: Sorafenib for treatment of hepatocellular carcinoma: a systematic review. Dig Dis Sci 57: $1122-1129,2012$

101.Zhu AX: Development of sorafenib and other molecularly targeted agents in hepatocellular carcinoma. Cancer 112: 250-259, 2008

102. Liu L, Cao Y, Chen C, Zhang X, McNabola A, Wilkie D, Wilkie S, Wilhelm S and Lynch M: Sorafenib blocks the $\mathrm{RAF} / \mathrm{MEK} / \mathrm{ERK}$ pathway, inhibits tumor angiogenesis, and induces tumor cell apoptosis in hepatocellular carcinoma model PLC/PRF/5. Cancer Res 66: 11851-11858, 2006.

103. Llovet JM, Ricci S, Mazzaferro V, Hilgard P, Gane E, Blanc JF, de Oliveira AC, Santoro A, Raoul JL, Forner A, et al; SHARP Investigators Study Group: Sorafenib in advanced hepatocellular carcinoma. N Engl J Med 359: 378-390, 2008.

104. Cheng AL, Kang YK, Chen Z, Tsao CJ, Qin S, Kim JS, Luo R, Feng J, Ye S, Yang TS, et al: Efficacy and safety of sorafenib in patients in the Asia-Pacific region with advanced hepatocellular carcinoma: a phase III randomised, double-blind, placebo-controlled trial. Lancet Oncol 10: 25-34, 2009.

105. Pawlik TM, Reyes DK, Cosgrove D, Kamel IR, Bhagat N and Geschwind JF: Phase II trial of sorafenib combined with concurrent transarterial chemoembolization with drug-eluting beads for hepatocellular carcinoma. J Clin Oncol 29: 3960-3967, 2011.

106. Wang SN, Chuang SC and Lee KT: Efficacy of sorafenib as adjuvant therapy to prevent early recurrence of hepatocellular carcinoma after curative surgery: A pilot study. Heptatol Res 44: 523-531, 2014

107. Kim R, Menon N and Aucejo F: Safe use of sorafenib in a patient undergoing salvage liver transplantation for recurrent hepatocellular carcinoma after hepatic resection. Med Oncol 28: 1044-1047, 2011.

108. Kudo M: Adjuvant therapy after curative treatment for hepatocellular carcinoma. Oncology 81 (Suppl 1): 50-55, 2011.

109. Kusano H, Ogasawara S, Akiba J, Nakayama M, Ueda K and Yano H: Antiproliferative effects of sorafenib and pegylated IFN- $\alpha 2 \mathrm{~b}$ on human liver cancer cells in vitro and in vivo. Int $\mathrm{J}$ Oncol 42: 1897-1903, 2013

110. Wang L, Jia D, Duan F, Sun Z, Liu X, Zhou L, Sun L, Ren S, Ruan Y and Gu J: Combined anti-tumor effects of IFN- $\alpha$ and sorafenib on hepatocellular carcinoma in vitro and in vivo. Biochem Biophy Res Commun 422: 687-692, 2012.

111. Huang G, Lai EC, Lau WY, Zhou WP, Shen F, Pan ZY, Fu SY and Wu MC: Posthepatectomy HBV reactivation in hepatitis B-related hepatocellular carcinoma influences postoperative survival in patients with preoperative low HBV-DNA levels. Ann Surg 257: 490-505, 2012.

112. Su CW, Chiou YW, Tsai YH, Teng RD, Chau GY, Lei HJ Hung HH, Huo TI and Wu JC: The influence of hepatitis B viral load and pre-s deletion mutations on post-operative recurrence of hepatocellular carcinoma and the tertiary preventive effects by anti-viral therapy. PloS One 8: e66457, 2013

113. Albert A, Brunetto MR, Colombo M and Craxì A: Recent progress and new trends in the treatment of hepatitis B. J Med Virol 67: 458-462, 2002.

114. Takkenberg RB, Weegink CJ, Zaaijer HL and Reesink HW: New developments in antiviral therapy for chronic hepatitis B. Vox Sang 98: 481-494, 2010. 